\title{
Cuba, desarrollo, dependencia y HETEROGENEIDAD ESTRUCTURAL
}

\author{
Edel J. Fresneda ${ }^{1}$ \\ Fecha de recepción: 07 de diciembre de 2015. Fecha de aceptación: 02 de mayo de 2016.
}

\begin{abstract}
RESUMEN
Este artículo reexamina la estrategia de desarrollo prevaleciente en Cuba, observando las variables de dependencia y heterogeneidad estructural. Busca distinguir cómo, a pesar de haber existido una desconexión política en la isla, su estrategia de desarrollo socialista enfrenta retos significativos que están determinados por el grado de heterogeneidad de su economía y por la profundidad de su dependencia al sistema de intercambio mundial. Como desafíos más importantes para la estrategia de desarrollo prevaleciente, se denotan: a) evaluar los efectos de la incorporación de actores supranacionales en los marcos de una heterogeneidad estructural, por la insuficiencia de financiamientos y capital; y b) proponer un desarrollo endógeno a partir de la incorporación del capital humano logrado en la isla.
\end{abstract}

Palabras clave: heterogeneidad estructural, dependencia, centro-periferia, desarrollo económico, relaciones internacionales.

Clasificación JEL: B51, E65, F51, N16, O11.

\section{Cuba, Development, Dependency, and Structural Heterogeneity}

\begin{abstract}
This paper reexamines the prevailing development strategy in Cuba, observing the variables of dependency and structural heterogeneity. It aims to elucidate how, despite a political disconnect on the island, its socialist development strategy is encountering significant challenges driven by the degree of heterogeneity in its economy and the depth of its reliance on the global system of exchange. Some of the most significant challenges facing the prevailing development strategy are as follows: $a$ ) how to evaluate the effects of the incorporation of supranational actors into the frameworks of structural heterogeneity, due to the insufficiency of financing and capital; and b) how to achieve endogenous growth beginning with the incorporation of human capital achieved on the island.
\end{abstract}

Key Words: Structural heterogeneity, dependency, center-periphery, economic development, international relations.

${ }^{1}$ Consejo Nacional de Ciencia y Tecnología, México. Correo electrónico:

edel.fresneda@gmail.com 


\section{CUBA, DÉVELOPPEMENT, DÉPENDANCE ET HÉTÉROGÉNÉITÉ STRUCTURELLE Résumé}

Cet article réexamine la stratégie de développement prédominante à Cuba, et observe les variables de Dépendance et Hétérogénéité structurelle. Il cherche à distinguer comment, bien qu'il y ait eu une déconnexion politique dans l'île, sa stratégie de développement socialiste affronte des défis significatifs qui sont déterminés par le degré d'hétérogénéité de son économie et la profondeur de sa dépendance vis-à-vis du système d'échange mondial. Parmi les plus importants défis pour la stratégie de développement prédominante, se détachent : a) celui d'évaluer les effets de l'incorporation d'acteurs supranationaux dans les cadres d'une hétérogénéité structurelle, du fait de l'insuffisance de financements et capital ; et b) celui de proposer un développement endogène à partir de l'incorporation du capital humain obtenu dans l'île.

Mots clés: hétérogénéité structurelle, dépendance, centre-périphérie, développement économique, relations internationales.

\section{CUBA, DESENVOLVIMENTO, DEPENDÊNCIA E HETEROGEINIDADE ESTRUTURAL Resumo}

Este artigo reexamina a estratégia de desenvolvimento que prevalece em Cuba, observando as variáveis de Dependência e Heterogeneidade estrutural. $\mathrm{O}$ artigo busca distinguir como, apesar de ter existido uma desconexão política na ilha, sua estratégia de desenvolvimento socialista enfrenta desafios significativos que estão determinados pelo grau de heterogeneidade da sua economia e pela profundidade de sua c ao sistema de intercâmbio mundial. Como desafios mais importantes para a estratégia de desenvolvimento que prevalece, encontramos: $a$ ) avaliar os efeitos da incorporação de atores supranacionais no marco de uma heterogeneidade estrutural, pela insuficiência de financiamento e de capital; e $b$ ) propor um desenvolvimento endógeno a partir da incorporação de capital humano conseguido na ilha.

Palavras-chave: heterogeneidade estrutural, heterogeneidade, centro-periferia, desenvolvimento econômico, relaçôes internacionais.

\section{古巴：发展，依赖性和结构异质性}

摘要

本文将着眼于依赖性和结构异质性这两个因素重新分析古巴现行发展战 略。本文试图指出：尽管古巴面临政治隔离, 其社会主义发展战略的挑战 由其经济的异质程度和其对世界贸易体系的依赖程度决定。现行主导发展 战略中最重要的挑战由：a）衡量由于融资不足而将超国家行为体纳入结 构异质的带来的影响；b）制定以岛上人力资源为基础的内源性发展。

关键词: 结构异质性, 依赖性, 中心一边缘, 经济发展, 国际关系 


\section{INTRODUCCIÓN}

Eric Hobsbawm concluyó su libro Historia del siglo XX con un lóbrego examen sobre la época histórica que, según su apreciación, culminó a finales de los años ochenta del mismo siglo. En él advertía sin soslayar cierta consternación axiomática, sobre que una herencia de la época que finalizaba era un raciocinio común a nivel global que evidenciaba la ausencia de alternativas. Con ello, y ante la utopía de una sociedad transformada, desde su punto de vista el precio de ese fracaso sería la oscuridad (Hobsbawm, 1994: 576).

Como características, la nueva época manifiesta una creciente relevancia de las representaciones sociales sobre movilidad y bienestar asociadas al consumo; además, la aquiescencia de las metas individuales en detrimento de las comunes en sociedad. Estas, podrían ser interpretadas como secuelas de esa opacidad que describe el historiador. En la aceptación universal y generalización de las mismas, influyen el desarrollo tecnológico y las comunicaciones.

En virtud de ello, se ha globalizado una perspectiva a favor de intereses individuales basados en estimaciones aprehendidas sobre qué es el bienestar, que soslaya las lógicas disruptivas que promueven otros valores. ${ }^{2}$ Con ello, es verificable una anomia progresiva que es expresión de la lasitud de los estímulos sociales respecto a estrategias inclusivas, de gobernanza, responsables ambientalmente, solidarias o de bienestar humano. La preocupación relativamente universal por satisfacer necesidades inmediatas -así visualizadas por los sujetos-, sin examinar cuáles serán las secuelas socioeconómicas y ambientales de ello para las generaciones futuras, plantea un reto para el desarrollo económico y social de las naciones.

Dentro de esa reconfiguración global, los costos sociales crecen como resultado de la brecha entre: la anomia sistémica que simboliza la prevalencia de intereses de rentabilidad dentro de un marco institucional normativo -que internacionalmente, exacerba un tipo de solidaridad utilitaria-, y las alternativas políticas y económicas eficientes en generar soluciones que mitiguen los efectos de esa característica particular. En el plano individual, esto podría traducirse en la perspectiva de rendimientos que tienen los individuos respecto a su propia vida, los cuales se materializan a través de los ingresos y el consumo principalmente. capacidades para lograr una vida digna. Véase Sen (1998 y 1999). También lo es el Desarrollo Sustentable. Véase Informe Bruntland. Our Common Future. onu (1987) <http://www.undocuments.net/ocf-02.htm> 
En este sentido, la pobreza y la ausencia de bienestar son brechas resultantes de la relación entre los intereses de rentabilidad y la solidaridad utilitaria a nivel global. Son las naciones dependientes y/o ubicadas en la periferia del capitalismo global, las que manifiestan una mayor exacerbación de las contradicciones y los conflictos humanos relativos a esos fenómenos. Aun cuando la pobreza y el bienestar son conceptos cuya relatividad refiere mayormente dinámicas endógenas o nacionales de concentración y distribución de la riqueza, las brechas sociales se amplían evidenciando la desintegración social. En consecuencia, cuando los estímulos sociales están vinculados a nivel global y con un referente no adecuado a las realidades de un país o nación, no respaldan iniciativas, o lo hacen de manera parcializada, que impliquen un cambio estructural con un sentido de transformación de la sociedad. ${ }^{3}$

Ese sentido común de sobrevivencia individual, ${ }^{4}$ expone la incapacidad de las instituciones para resolver conflictos referidos al bienestar. También, refleja una moralidad selectiva en lo político (labilidad institucional), que hace uso de las consecuencias sociales sin atenuar los problemas referidos a la desigualdad, el desarrollo de capacidades, el acceso a servicios básicos e ingresos.

Un caso particular dentro del área latinoamericana, que hoy refleja la contradicción, por un lado, de la anomia sistémica definida por estímulos sociales exógenos y, por otro, de la subsistencia de una estrategia política y social que propone "otros" valores, es el de Cuba. En la coyuntura cubana actual, se manifiesta una crisis en la que los logros de Desarrollo Humano (DH) están enfrentados a un raciocinio que basa sus expectativas de bienestar a través de rendimientos representados en la capacidad de consumo y el ingreso. Las causas de esa crisis se plasman a través del mantenimiento de la Heterogeneidad Estructural (HE) y la dependencia al sistema mundial.

Esta última afirmación viene a descubrir lo que podría ser catalogado como la principal contradicción de la estrategia aun prevaleciente en Cuba: esto es, haber creado capacidades sociales $\left(\mathrm{C}_{\mathrm{S}}\right)$-sería la sumatoria de indicadores de DH más las políticas públicas-, que no encontraron en los marcos regulatorios, ni en los procesos políticos, ni en la economía, oportunidades para desarrollar habilidades y competencias adquiridas.

Stiglitz (1998) entiende el desarrollo como una transformación de la sociedad. Véase Stiglitz (1998).

Hobsbawm (1994), le llama "valores de un individualismo asocial absoluto, tanto en la ideología oficial como privada", en la que predominan individuos desconectados entre sí, que persiguen su propia gratificación como tendencia social. 
Esta contradicción refiere un error tácito que ha perpetuado la HE en la isla y que también ha acentuado el alcance de la dependencia hacia el entorno global. Esta se entiende como la principal causa, porque hubo en efecto una disociación política respecto al predominio de intereses de rentabilidad a escala global por más de medio siglo -también conteniendo un conflicto político con Estados Unidos.

En síntesis, en este caso particular, al no aprovecharse las capacidades sociales-que no se traducen solamente en educación formal y salud de la fuerza de trabajo, sino también por la capacidad de innovación, capacidad de reproducción social y emprendimientos-, se mantuvo una estructura productiva periférica que históricamente ha limitado la reproducción socioeconómica del país, con encadenamientos productivos ineficientes y con una baja productividad y bajos ingresos. Este último aspecto incide en la presencia de una limitación relativa del consumo, ${ }^{6}$ que es causa de la anomia sistémica que se manifiesta dentro de la estrategia política prevaleciente, siendo la migración de la fuerza de trabajo un consecuencia visible.

El actual proceso de reconexión de la isla al sistema de intercambio mundial, legitima las cuestiones de: cuán eficiente fue la alternativa política que representa la isla en generar soluciones endógenas eficientes que disminuyeran, por una parte, la influencia de los intereses de rentabilidad y la solidaridad utilitaria; y por la otra, en generar estrategias de desarrollo que superaran la HE y la dependencia. Tienen especial significado para el presente cubano: a) la ausencia de grupos económicos con lógicas capitalistas en lo interno;

oportunidades para tener o desarrollar una vida digna. El Índice de Capacidad Social en un contexto dado, puede medirse a través de la división entre: $a$ ) el nivel de $\mathrm{DH}\left(\mathrm{B}_{\mathrm{h}}\right)$ más aspectos sociales como las políticas públicas, población vulnerable, acceso a servicios y otros indicadores $\left(\mathrm{S}_{\mathrm{o}}\right), \mathrm{y}$ b) la sumatoria de Economía ( $\mathrm{E}_{\mathrm{c}}$ cadenas de producción y distribución de bienes, encadenamientos productivos, cadenas de valor, consumo, ingresos, porcentaje de empresas privadas o estatales, empleo, intensidad en el uso de materias primas, intensidad en el uso de recursos materiales, transporte, uso de tecnologías, productividad, innovación, entre otros indicadores; -más Política $\left(\mathrm{P}_{\mathrm{o}}\right)$-marcos regulatorios, descentralización, inclusión en la toma de decisiones, entre otros indicadores; más Ambiental $\left(\mathrm{A}_{\mathrm{m}}\right)$, -son los recursos, las características ambientales y ecológicas de una nación útiles para mejorar la calidad de vida de sus habitantes: área boscosa o de reserva natural, área cultivada, calidad de los suelos, calidad del aire, erosión, niveles de contaminación, desechos sólidos, acceso a espacios públicos, sustitución de tecnologías, entre otros indicadores. Aunque no es objetivo del presente artículo, se presenta una fórmula preliminar en la que aún se trabajan los indicadores: $\left(\mathrm{IC}_{\mathrm{s}}=\Sigma\left(\mathrm{B}_{\mathrm{h}}, \mathrm{S}_{\mathrm{o}}\right) / \Sigma\left(\mathrm{E}_{\mathrm{c}}, \mathrm{P}_{\mathrm{o}}, \mathrm{A}_{\mathrm{m}}\right)\right.$

6 Que puede ser entendida como una privación relativa al incidir en la sociedad cubana, normas y valores de consumo relacionadas con el capitalismo a nivel global más enfocada al consumo de bienes y menos a accesos a servicios y alimentación. 
b) la disminución de brechas sociales con la reducción de la desigualdad y la pobreza, y c) que los alcances de DH no fueron factores que permitieron cambiar la posición periférica de la isla en el sistema mundial.

En tal sentido, dentro de los desafíos actuales para Cuba están: a) evaluar los efectos de la incorporación de actores supranacionales -que reproducen un tipo de geopolítica-, en los marcos de una HE, por la necesidad de búsqueda de financiamientos y capital; y por otra parte, b) proponer un desarrollo endógeno con logros de productividad y progreso tecnológico a partir de la incorporación de las capacidades sociales logradas en la isla. Este último aspecto con especial relevancia para atender a los estímulos sociales que reconfiguran lógicas de desarticulación como: el crecimiento de las desigualdades y la pobreza y el decrecimiento de los ingresos, en un contexto global donde la percepción de movilidad social se relaciona con el consumo. Todo ello en un ambiente de DH.

Estos desafíos que enfrenta Cuba en el presente, ponen sobre la mesa algunas de las discusiones teóricas contenidas en las contribuciones de las ciencias sociales latinoamericanas. Por ello, a partir de la determinación de las diferencias y similitudes relativas a cómo se ha mantenido la HE y la dependencia en Cuba y cuáles han sido los objetivos de desarrollo y los actores involucrados en ellos, en el presente análisis se tiene como objetivo repensar el presente cubano a través los aportes teóricos latinoamericanos. Ello como una necesidad para superar la HE y la dependencia que es verificable en la isla y también en algunos de los estados periféricos que componen la región.

\section{LA HEREJÍA DEL SOCIALISMO O LA SOLUCIÓN POSPUESTA}

Bajo un prisma heterodoxo podría afirmarse que la concepción de desarrollo asumida por Cuba en 1961 estuvo condicionada por conflictos exógenos y endógenos. Ello se explica por el contexto histórico en que emerge la Revolución cubana, al desarrollarse como un proceso resultante de un movimiento nacionalista que se gesta desde 1930, que cuestiona el reacomodo de formas tradicionales de poder en una concepción moderna de transformación, asume la concepción marxista posteriormente para explicar la contradicción entre el capital y el trabajo y la explotación de la fuerza de trabajo, no sin excluir la metamorfosis gnoseológica leninista y estalinista del marxismo (Martínez Heredia, 2005 y 2008).

Como es conocido, Cuba fue objeto de la expansión capitalista en 1898. Este proceso, que vino a acentuar las formas típicas de supeditación económica en tanto nación periférica, reprodujo en cierto grado el reacomodo de las 
élites y del sistema productivo que fueron configurados bajo la égida de la colonia española. Las formas de incorporación de un actor central como Estados Unidos -que vino a consolidar la especialización productiva, la supeditación al comercio mundial, y los mecanismos por medio de los cuales se reproducían la HE y la dependencia-, dieron pie a la conformación de una tendencia nacionalista. Dentro de ella, algunos sectores de la burguesía nacional pretendían un crecimiento económico alternativo a la producción de bienes primarios. En la génesis de la Revolución coexistió esa tendencia como una concepción moderna de transformación, donde la industrialización, la reforma agraria, los ingresos, la desigualdad y la defensa de la propiedad privada, fueron argumentos que aglutinaron a diferentes fuerzas sociales en un proceso de subversión. ${ }^{7}$

No obstante, este proceso de subversión emergía en una etapa condicionada internacionalmente por el conflicto de la Guerra Fría, en la que, el actor externo que había perpetuado la condición de periférica o de colonialidad $^{8}$ hasta ese momento -léase Estados Unidos-, percibió el proceso subversivo como una pérdida de un área de influencia en lo que consideró históricamente como su traspatio natural. ${ }^{9}$ Por ello, la disyuntiva histórica de la dependencia económica cubana en los ańos sesenta del siglo xx, fue la alianza con la contraparte principal del conflicto de la Guerra Fría. Con ello, al mismo tiempo que se convertía Cuba en referente para Latinoamérica, a partir de las rupturas generadas con una relación dependiente en lo político, la dependencia económica se readaptaba a formas de intercambio con el llamado socialismo real. Formas, que perpetuaron la HE a partir de una organización de la producción en la que el Estado asumía el control de los procesos.

Una consecuencia de lo anterior, en la estrategia de desarrollo de la isla, fue que desde la metamorfosis leninista del marxismo se estableció una percepción excluyente sobre actores internos que, por su naturaleza, debían ser incorporados para generar logros ostensibles en el crecimiento de la productividad endógena. La percepción que velaba sobre los oportunismos burgueses, discriminaba entre élites y no élites y concebía estrategias de desarrollo planificadas y centralizadas, que incidían especialmente en el alcance de agen-

7 Estas discusiones estaban contenidas en el debate de la época. Véase Portell Vilá (1943, 1943a) y Sánchez Arango (1960).

8 En Latinoamérica la colonialidad del poder se asume como un traspaso de formas de poder de grupos tradicionales a otros con los que se mantienen intereses comunes. Véase Quijano (2000).

9 La explicación sobre este tipo de relaciones internacionales, se fundamenta en elementos como la Doctrina Monroe, la Enmienda Platt, la Política de Buen Vecino y el Big Stick. Véanse opiniones que propone Lowenthal (1991). 
cias con intereses individuales en la amplitud de la economía. Esta actitud, al mismo tiempo que refrendaba una desconexión con los modelos de expansión geopolítica al quebrantar la ascendencia de grupos sociales con intereses de rentabilidad en lo interno, significó una ralentización de la capacidad endógena para generar estrategias propias de producción. La eliminación gradual de la capacidad operativa de las agencias individuales y la propiedad privada en la conformación de nexos intersectoriales o encadenamientos productivos, fue un proceso político que tuvo consecuencias económicas para la estrategia de desarrollo de la isla. La capacidad de la gestión individual o propia en el crecimiento de la productividad, es una de las cuestiones más debatidas en la actualidad cubana.

Ciertamente, el socialismo implicaba para la economía heterogénea y dependiente cubana una modificación de las estructuras prevalecientes; mas, esa transformación no involucraba íntegramente un reacomodo sobre las necesidades de desarrollo del país, que eran: crear las bases endógenas para romper con la HE y la dependencia, incluyendo actores cuya potencialidad hiciera eficiente el cambio. Las estrategias de desarrollo más bien respondían y eran sostenidas por intereses de otros actores supranacionales. Esos actores, dentro del ámbito del así llamado socialismo real -bajo otra lógica de expansión geopolítica-, crearon una perpetuación de la dependencia a través de la transferencia de recursos, bienes intermedios de producción y de tecnologías, instituyendo un espejismo de desarrollo. Con estos recursos, Cuba progresó en la eliminación de las desigualdades sociales y en la creación de uno de los indicadores de las capacidades sociales: capital humano.

Un aspecto controversial aquí, es que las decisiones económicas centralizadas marcadas por un conflicto político y la exigua participación de diferentes actores económicos y sociales en esas decisiones, generó un esquema productivo ineficiente, siendo una consecuencia de ello que, la satisfacción de necesidades humanas en lo interno del país dependía de procesos externos de compensación.

Una afirmación cuestionable es que: si bien la estrategia de desarrollo socialista desde las políticas sociales generó un DH con potencialidades para desenvolver cambios tecnológicos y productividad -que es medible en la creación incremental de capacidades en la población-, ese tipo de desarrollo no contribuyó eficientemente a la superación de la desarticulación de los sectores productivos. Ello, porque su potencialidad de innovación no tenía más incentivos que los del ingreso asociado a una política de pleno empleo en un ambiente de baja productividad. 
Visto desde otra óptica, bajo la lógica de intercambio socialista, el sostenimiento de estrategias productivas y económicas que nutrieron la exportación de bienes primarios sin valor agregado, evidenció el soslayo a las capacidades de innovación del DH y sobre los incentivos para la innovación, perpetuando así la baja fortaleza de los encadenamientos entre sectores. ${ }^{10}$

Una consecuencia de ello en la actualidad, que es tautológicamente irónica, encerrada en la desarticulación entre el sector tradicional de la economía y el moderno, ha sido la afectación de los indicadores de DH que, en efecto, fueron logrados en la condición de heterogeneidad. Esta contradicción resultante de otra contradicción, se expresa con la existencia de políticas públicas o sociales de amplio alcance, con accesos universales a servicios básicos para satisfacer necesidades humanas y tener una vida digna; al mismo tiempo del crecimiento de la desigualdad y la pobreza como resultado de esa heterogeneidad. Esto es, la limitación del crecimiento de los ingresos reales e indirectos al no haber productividad. Con ello, la afectación del consumo, en un contexto internacional en el que las nociones más generalizadas de movilidad social se asocian precisamente al acceso a formas de consumo provenientes de países centrales y acceso a tecnologías.

La herejía del socialismo, hablando en términos de desarrollo, fue sobrevalorar el rol del Estado y menospreciar el alcance de los intereses nacionales e individuales, el rol del mercado bajo una concepción de regulación, el alcance de las pequeñas y medianas empresas y de la propiedad privada, en la interrelación entre: a) la capacidad de crecimiento de los sectores modernos y entrelazamiento con los tradicionales, $b$ ) los encadenamientos productivos, los ingresos y la conformación del capital humano, $c$ ) la productividad e innovación para el cambio estructural.

La errata para la trayectoria del desarrollo cubano que se esboza en el actual presente, supone un soslayo a las experiencias pasadas, en tanto se buscan alternativas que parecen redimir la incorporación de actores externos que son consecuentes con sus intereses de rentabilidad y con su influencia en grados diversos de solidaridad utilitaria en toda la región latinoamericana. Actores que sí pueden ser proveedores de financiamientos, lo cual ampliaría la deuda externa, aumentando la contracción del ahorro interno; que sí podrían mejorar sectores específicos a partir de la transferencia tecnológica, pero sin intereses en crear encadenamientos a otros ámbitos de la economía; que sí

10

Actualmente el sector biotecnológico tiene gran desarrollo pero no articula encadenamientos eficientes con otros sectores en un sistema empresarial centralizado que ha sido una característica del sistema productivo. Véase Vidal (2008 y 2009). 
pueden resultar proveedores de bienes con valor agregado para una economía que tiene un déficit comercial crónico.

Como en el resto de Latinoamérica, sigue siendo una solución pospuesta la emergencia de una estrategia de desarrollo económica, endógena, eficiente, depositaria y competitiva frente a actores supranacionales. Esta postergación, parece ser una causa importante del por qué la HE se mantuvo al mismo tiempo que la dependencia. Irónicamente, bajo un desempeño político independiente en relación a los intereses de los países dominantes.

\section{¿LA HISTORIA QUE VUELVE?}

Dos aspectos que parecen ser una constante en el pasado y presente de la isla, y que matizan la evolución futura de la estrategia de desarrollo prevaleciente, es la dependencia a las importaciones y la vulnerabilidad frente los términos de intercambio. Estos elementos, han obligado a: en primer lugar, replantearse la incorporación de actores externos en el presente, alguno de los cuales incluso, han sido objeto de la configuración política del sistema prevaleciente en la isla. En segundo, a sobrevalorar el rol de la inversión externa para mantener el consumo interno de bienes y la producción. Como en el resto de la región latinoamericana, la capacidad de importación sigue siendo un óbice para una efectiva estrategia de desarrollo endógena.

Esa necesidad de capacidad de importación, ha generado endeudamientos externos crecientes. En el caso de Cuba, sin acceso a la mayoría de las instituciones crediticias internacionales, se han diseñado soluciones coyunturales que buscaron superar el déficit comercial y las consecuencias de la HE para sostener esa capacidad para importar. Dentro de esas soluciones están: a) el uso creciente de la remesa a partir de un proceso migratorio agudizado en las últimas décadas; b) la concertación de formas de intercambio beneficiosas con otras naciones que no dejan de ser compensatorias -como es el caso de Venezuela-, y c) con la exportación de servicios intensivos que supone un desaprovechamiento de las capacidades sociales en el desarrollo endógeno, al ser exportado como un activo redituable de la economía.

Sigue siendo una contradicción el hecho de que la economía presente deficiencias descritas por el Capital Humano de la isla. A modo de ejemplo, existe una inseguridad alimentaria, que no significa hambruna, sino limitaciones en la producción de alimentos teniendo ingenieros agrónomos y biotecnólogos capaces de desarrollar estrategias productivas eficientes. 
Más allá de que estas soluciones tienen un carácter perentorio y que es notoria la ausencia de soluciones productivas endógenas, es preciso destacar que en sintonía con lo que ocurrió en otros países de la región, el endeudamiento externo ha significado un estancamiento de la estrategia de desarrollo prevaleciente en la isla. No obstante, incluso, a la renegociación de deudas importantes como lo fueron los casos de de Rusia y México.

Mientras que este estancamiento en la región generó el establecimiento de políticas de ajuste macroeconómico que orientaron el tránsito hacia el neoliberalismo, matizadas por las renegociaciones con el Fondo Monetario Internacional (FMI); en el caso de Cuba, se estableció una Actualización del Modelo Económico Socialista, que entre otras cosas, induce a la readecuación de las políticas públicas a formas más eficientes de distribución de la riqueza y que implican una descarga de los recursos utilizados en las políticas públicas hacia la sociedad en general, aunque dentro de una lógica socialista.

Aquí es importante destacar la situación de quiebre autonómico que representa el estancamiento. Tanto en Cuba como en Latinoamérica, en la nueva época que representa el siglo XXI, se presenta una situación negativa respecto a la rentabilidad del capital (o de los excedentes), que fortalece la dependencia hacia actores exógenos. En el caso de Cuba, esa situación desempolva una contradicción tácita, relacionada con cuáles han sido los actores que históricamente han desempeñado un rol central en el sostenimiento de la condición periférica y cómo la isla ha de relacionarse con ellos en su proceso de reinserción. Contradicción que, a la luz de los recientes acuerdos con Estados Unidos, parece poner en tela de juicio la maniquea concepción de imperialismo ${ }^{12}$ sobre la cual se instauró socialismo en la isla.

El dilema de la geopolítica de la apropiación diferencial de la riqueza o de las fuerzas heterónomas que conducen a la dependencia parecía superado. Este dilema también parece cuestionar al nivel de las representaciones sociales las fortalezas de una concepción socialista, que define el bienestar como acceso a condiciones de vida dignas y creación de capacidades; para enfrentar lo que Scribano (2008) plantea como "una metamorfosis del poder al nivel de las relaciones sociales". Esto es, estímulos sociales que representan la movilidad social y el bienestar a través de sensaciones de acceso a consumo provenientes de países centrales, quedando la acción social sometida a fuerzas heterónomas, ${ }^{13}$

\footnotetext{
12 13

Fundamentalmente hace referencia a las tesis leninistas. Véase Lenin (1902).

No queda claro en la estrategia de desarrollo que eclosiona con la reinserción de la isla al sistema de intercambio internacional, cuáles son los caminos endógenos para lograr críticamente una disociación de las fuerzas heterónomas que condicionan la condición periférica.
} 
no del todo palpables (Scribano, 2008), y que van reproduciendo una solidaridad utilitarista en ausencia de clases o grupos que concentran el ingreso como resultado de actividades productivas.

De esa manera, es factible anticipar una probable devaluación de lo que representa la independencia política, como un costo palpable en el sentido común y las representaciones sociales de las generaciones más jóvenes en la isla, mientras que se interponen sistemas de interacción social que perciben como válidos, aquellos valores o significados relacionados con el consumo y asociados al capitalismo.

El dilema de la independencia, como en Latinoamérica, ${ }^{14}$ atraviesa en el caso cubano la disyuntiva de cómo potenciar la acumulación endógena desde la periferia, frente a nuevas modalidades de imperialismo en el mundo. Nuevas modalidades que, en la era de globalización, contienen formas indeterminadas de acción (Scribano, 2008). Desde un punto de vista estructuralista, esto se traduce en cuáles cambios son necesarios para disminuir la influencia del centro (Prebisch, 1949 y 1963). ${ }^{15}$ Ello pone sobre la mesa la relevancia -o eclosión necesaria- de un sector económico en el socialismo, cuyos intereses resulten prioritarios a los exógenos. Aspecto que colisiona con la hegemonía estatal -y la mentalidad institucionalizada-, en los procesos productivos. Esta es una idea que resulta difícil de asimilar en un contexto que ha resultado ajeno a los emprendimientos, con una tendencia a anatemizar la propiedad privada y con una ausencia relativa de agencias o empresas con una lógica propia.

Esa eclosión necesaria, indefectiblemente, cuestiona la histórica exclusión de la propiedad privada o la supresión de agencias con lógicas propias en el modelo económico cubano. Además, conduce a prever como una solución plausible la incorporación de actores nacionales que cuentan con un capital de conocimiento -sobre todo dentro de la isla-, y con capital para financiar

Véase Galeano (1971).

15 Raúl Prebisch en su texto El desarrollo económico de A. Latina y algunos de sus principales problemas desafía los supuestos imperantes sobre el comercio internacional desde un pensamiento estructuralista y la inserción de A. Latina en los términos de intercambio de los bienes primarios. Este texto, paradójicamente, fue presentado en la Conferencia de La Habana de 1949. En él se cuestionaba la división internacional del trabajo y conminaba a una participación más activa del Estado en el proceso de industrialización, para así, eliminar la dependencia y generar una política anticíclica que implicaba desplazamientos de factores productivos, no siempre fáciles de realizar. El crecimiento de la población en edad productiva era uno de los factores que podrían atenuar los estancamientos. 
cambios económicos -sobre todo el componente migratorio cubano fuera de la isla en su conjunto. ${ }^{16}$

Lo que ocurre en la práctica es que, a diferencia de Latinoamérica, en el presente cubano no son nítidas clases o grupos sociales que se beneficien, acumulen y enriquezcan gracias a las alianzas con los países dominantes, tal y como lo describe la Teoría de la Dependencia. ${ }^{17}$ De hecho, es un país, donde esos vínculos se han roto con la Revolución. Por ello, resultaría interesante valorar cómo han de configurarse relaciones económicas virtuosas, con marcos de regulación que hicieran confluir los intereses de los países centrales y del Estado cubano en lo relativo a la rentabilidad del capital en la isla.

Otra cuestión no menos relevante, es cómo la estrategia socialista periférica ha de superar su incapacidad de fuentes de financiamiento por medio de la inversión extranjera, sin que ello signifique admitir procesos de explotación gradual de la fuerza de trabajo. ${ }^{18}$ También, eso remite a un cuestionamiento sobre los principios de contradicción clasista que legitiman la opción socialista.

Los desequilibrios financieros, macroeconómicos y monetarios, han estado disociados de las políticas sociales y el apoyo a sectores sociales desprotegidos. $\mathrm{Al}$ mismo tiempo, en la isla sobrevive la necesidad de inversión y de industrialización con el apoyo de actores supranacionales cuya tendencia es potenciar la aquiescencia del mercado como regulador. Fórmula que en un grado amplio, es una de las causas más importantes de los problemas sociales en la región.

Como resumen de este complejo panorama, queda la disyuntiva de cómo lograr un sostenimiento e incluso mejoramiento de la formación de capacidades sociales en una coyuntura de crisis económica y expectativas generalizadas de consumo en la isla. Esta es una realidad compleja que requiere de solucio-

Es probable que esta última cuestión refiera a las discusiones sobre migración y desarrollo, y a la evaluación de cuál es el rol de los migrantes en las estrategias de desarrollo. Sin profundizar mucho aquí, esta es una solución que se define en marcos de cogobernanza, de integración social y en la inclusión participativa de los actores sin negar la responsabilidad y rol del Estado en una estrategia de desarrollo socialista.

Los que asumen en la Teoría de la Dependencia a los factores externos como determinantes del subdesarrollo y la dependencia son: Andrés G. Frank, Osvaldo Sunkel y Celso Furtado. Dos Santos, define "condiciones externas" y determinantes internas. Fernando H. Cardoso por su parte favorece las relaciones internas como determinantes para entender el desarrollo dependentista. En gran medida subyacen conflictos ideológicos y de clase en las visiones y los elementos que consideran como preponderante los distintos autores, siendo las relaciones sociales de producción y los conflictos de clase factores que generaron discusiones y controversias dentro de la propia dependencia. Véase Kay (1989 y 1991). 
nes que deben volver puntualmente sobre qué significó el advenimiento de la modernidad en la nación caribeña. Un antecedente importante de ello, es la visión admonitoria de José Martí.

\section{EL PRESENTE CUBANO EN EL PASADO Y FUTURO DE LA HETEROGENEIDAD ESTRUCTURAL LATINOAMERICANA}

En la comprensión de las dinámicas de desarrollo de América Latina, las ciencias sociales latinoamericanas tienen como aportes visibles: el estructuralismo y la Teoría de la Dependencia. El enfoque estructuralista, ${ }^{19}$ destacó que la inserción de los países del área, tenía como característica la exportación de materias primas con precios que perpetuaban una desventaja en el intercambio internacional y, con ello, la dependencia. De esa manera, desde el enfoque estructuralista, se definía una distancia entre los países centrales y periféricos. Estos últimos, con sectores heterogéneos que condicionaban las estrategias de desarrollo. ${ }^{20}$

El enfoque de la dependencia, por otra parte, profundizó en el estudio de las estructuras económicas y sociales que perpetúan la HE, siendo algunos de los aspectos más discutidos: el rol de la deuda externa en la capacidad de acumulación de las estrategias de desarrollo nacionales; la internacionalización del capital y el aumento de la inversión extranjera; las diferencias de productividad y de innovación y cómo éstas inciden en el proceso de industrialización y en las relaciones sociales, con la acentuación de la vulnerabilidad de los grupos desprotegidos frente a procesos de acumulación menos competitivos.

En lo relativo al análisis de la evolución de la HE y la dependencia -y las causas que las originan-, existen perspectivas que evalúan las particularidades presentes de esos procesos, y en relación a los acontecimientos económicos y políticos actuales que están matizados por el neoliberalismo. A modo de ejemplo, López y Belloni (2014) definen que en el presente Latinoamérica, se manifiesta una articulación entre las tendencias de re-estructuración de las lógicas de acumulación del capital a escala global y los proyectos nacionales de desarrollo. Rearticulación, que ha generado un "nuevo proceso" de depen-

19

Que surgió cuestionando la Teoría de la Modernización de Rostow y dentro de la que, sobresale el aporte de R. Prebisch.

20 Bajo este enfoque la economía global se compone por los vínculos que existen entre los sectores heterogéneos de los países periféricos, cada uno de los cuales tiene un rol específico en la rentabilidad del capital a escala global. 
dencia económica en los países de América del Sur y los diversos modelos de desarrollo a escala nacional. Entre las variables que dan cuenta de esta afirmación, están los flujos de Inversión Extranjera Directa (IED), que se han incrementado en la región, después del año 2000 del pasado siglo y hasta la fecha. ${ }^{21}$

Según López y Belloni (2014: 50) los proyectos post-neoliberales de desarrollo en América Latina, se "han construido sobre las bases creadas por el neoliberalismo". Entre ellas se destacan: el carácter transnacional del capital que hegemoniza el proceso de acumulación en la mayoría de los países de la región y la nueva dependencia asociada a la producción de commodities para la exportación.

Atendiendo a la evolución de la HE y la dependencia en la región, es cuestionable esta idea de López y Belloni (2014). Cuestionable, porque la transnacionalización del capital es un fenómeno que alcanza los niveles más altos en la última época, pero que ha existido como una constante necesaria para la acumulación capitalista y es, esta región, un espacio donde se ha manifestado este proceso de una manera más nítida después de la Segunda Guerra Mundial.

De esa manera, no es verificable una "nueva dependencia" que se traduce en la ampliación de la IED o en la especialización productiva asociada a la producción de mercancías primarias -o commodities-. Más bien, lo que es verificable es un proceso de expansión y ampliación de las causas que condicionan la HE, también con un sentido transnacional entre países periféricos y no sólo en un sentido vertical hacia países centrales; Cuba es un ejemplo de ello.

En este contexto, la re-primarización de las economías no alude a un proceso de abandono anterior de la producción de bienes primarios como tendencia en la región. Como refiere Svampa (2013) la sobreexplotación de los recursos naturales y de la fuerza de trabajo en el área, es un fenómeno de rancia data que adquiere formas de materialización diversas en los últimos años, a partir de la rentabilidad de las inversiones sobre la explotación de recursos naturales y los altos precios de las materias primas. ${ }^{22}$

21 22

Cepal (2013).

Una cuestión debatible aquí, es que la evolución de la heterogeneidad y de la dependencia en A. Latina, es un proceso continuo que ha matizado las relaciones internacionales y estrategias de desarrollo particularmente. Ocurre que las épocas históricas son clasificadas a partir de las particularidades que predominan, omitiendo en cierto grado la concatenación entre los distintos procesos que tienen lugar. Al definir, por ejemplo, una época post-neoliberal en Latinoamérica, se da cuenta de las consecuencias de esta tendencia política y económica a nivel internacional para la región, pero el concepto en sí conlleva necesariamente una descripción de los vínculos históricos entre los procesos que determinan la dependencia en tanto fenómeno recurrente. A modo de ejemplos: la existencia de grupos que favorecen la acumulación global perpetúa la enunciación 
En este sentido, por ejemplo, la tesis centro-periferia que contiene el análisis sobre el alcance del deterioro de los precios de intercambio (Prebish, 1948 y 1963), es útil para descubrir las distorsiones latentes de un sistema productivo insular, que no fue superado por la existencia independiente del EstadoNación. Sobre todo, si ese deterioro se encadena con la restricción actual en el desarrollo de tecnologías, la innovación y la productividad y con el proceso de producción de materias primas sin un valor agregado.

En tal caso, la lectura desde Cuba, permite entrever que la asunción del Estado como una agencia para el desarrollo, no resultó en un incentivo para la producción de bienes con valor agregado que permitieran una competencia equilibrada en el comercio internacional. De tal manera que, desde una condición heterogénea se perpetuó la condición periférica en el socialismo por el aislamiento que significó el intercambio preferencial con el así llamado socialismo real-que influyó en la posposición de la búsqueda de incentivos propios para la productividad aun cuando generó un capital humano. Además, por la no incorporación del capital de conocimiento logrado en la materialización de producciones competitivas en el intercambio o sustitutivas de las importaciones.

Esta última afirmación no conduce a una conclusión festinada sobre la condición de subdesarrollo como una etapa del desarrollo (según el modelo de Rostow $^{23}$ ) o, en otro sentido, a entender el desarrollo como crecimiento económico. Más bien, la aseveración da cuenta de que existe una característica visible en los países periféricos; la cual es: entender la HE como una condición estructural específica que es resultado de la evolución del capitalismo a nivel global. Condición que, como evidencia hoy el caso cubano, no se supera solamente con rupturas en un nivel político exclusivamente -el socialismo o la así llamada dictadura del proletariado no fragmentó del todo esa condición estructural-; siendo necesaria para esa superación (o cambio estructural), la interrupción de las causas de perpetuación y la reproducción de la dependencia externa y la HE.

En Cuba, en un sentido inverso a lo que Furtado (1964, 1966, 1984, 1993) reconocía como un proceso de irradiación desde el crecimiento a otros sectores de la economía y de la sociedad, se logró un desarrollo social como

de políticas nacionales que respalden ese interés; el atraso tecnológico y el escaso desarrollo de conocimiento, genera la dependencia a las innovaciones externas; la incapacidad de ahorro o acumulación por las deudas externas perpetúa la necesidad de IED; las consecuencias sociales de la acumulación concentrada extiende la estratificación social y la desigualdad. 
una evidencia de cambio estructural, aunque no sostenido endógenamente. Incluso, entendiendo el desarrollo como una categoría que implica alcances ostensibles en la satisfacción de las necesidades humanas, desde un sentido endógeno y equitativo, resulta necesario juzgar que ese concepto encierra un equilibrio entre el crecimiento económico y el progreso social. En Cuba, ante la ausencia de ese equilibrio, el cambio estructural no se materializa como resultado de la injerencia del Estado como agencia del desarrollo bajo condiciones específicas en cuanto a financiamiento y uso de recursos.

En lo relativo a esas condiciones particulares, lo cuestionable -y que pudiese ser entendido como una lección-, no es la estrategia de modificación de las estructuras capitalistas en la isla, que tenía como objetivo lograr la industrialización y el bienestar, sino el modo en que fue elaborada. A modo de ejemplo, la planificación desde el Estado para desarrollar una industrialización se basó en la importación de bienes intermedios de producción y de tecnologías que produjeron efectos aislados de desarrollo sin modificar las estructuras dependientes. Además, no hubo flexibilidad institucional a partir de las fronteras que suponían el marco ideológico de confrontación política internacional. De tal suerte que, como se explicó antes, el horizonte ideológico definió una exclusión de actores endógenos relevantes en la organización de la economía y modificación de las instituciones o de las estructuras. Actores -que no fueron otros sino aquellos con capacidad económica e ideológica para elaborar alternativas de desarrollo propias aunque individuales-, que dejaron de ser sujetos de la historia por el conflicto político y económico alrededor de la propiedad privada, aun cuando hubo un progreso social para la mayoría de la población con la distribución del ingreso.

De lo anterior es posible enunciar que, la concepción de desarrollo socialista tuvo como aspectos característicos en la isla, la existencia de un progreso social y de cambio cultural sin modificar profundamente las estructuras económicas. Se llegaron a satisfacer necesidades humanas sobre la base de esquemas relativamente bajos de productividad y de innovación. La diferenciación en el sistema productivo y la innovación, son aspectos que Furtado (1964) determina como imprescindibles para provocar un cambio estructural. ${ }^{24}$

También, desde esas condiciones particulares de intercambio que predominaron bajo el intercambio socialista, es posible reconocer un proceso rela- 
cionado con los ingresos y el mercado interno, que generó un estancamiento de la economía de manera diferenciada al resto de la región. Si bien, no hubo una concentración del ingreso en élites económicas internas de manera que se condicionaran los patrones de consumo disociados del grado de desarrollo de las fuerzas productivas, sí hubo una desviación al exterior de la potencialidad de acumulación aún con un intercambio a precios preferenciales. Esto tuvo que ver con la existencia de políticas de pleno empleo, con ingresos relativamente igualitarios que no dinamizaron la productividad o el mercado interno.

Al haber sido condición del socialismo el pleno empleo de sus trabajadores, sin adecuar los ingresos a los aportes productivos o tecnológicos de la fuerza de trabajo, se limitó la capacidad de incremento de la productividad, y con ello, de los ingresos. El círculo vicioso se expresa de la siguiente manera: al no haber productividad, los excedentes no eran incrementados, reduciéndose así la capacidad de acumulación o la tasa de inversión. Las mejoras en productividad no se transferían al productor en la empresa socialista y los excedentes se redirigían al sostenimiento externo de la capacidad productiva y al sostenimiento interno de las políticas sociales de amplio espectro. La consecuencia de ello, fue el mantenimiento tácito de una incapacidad estructural que afloró al comenzar el proceso de reinserción de la isla al comercio internacional en la década de los noventa del siglo xx.

Una cuestión no fehacientemente discutida en ese complejo proceso, lo es el cambio en los patrones de consumo cubano. Hecho que ha influido notoriamente en revelar las brechas entre productividad y acumulación o tasa de ganancia. Normas de consumo, que en no poca medida están matizadas por el fenómeno migratorio de la isla y por las estrategias de acumulación sostenidas por el Estado a partir del uso de la remesa, en ausencia de empresas transnacionales hasta ahora.

En esa incapacidad estructural, se observa, por una vía distinta, un proceso semejante al que describe Furtado (1964) en Dialéctica del subdesarrollo: un déficit en la realización efectiva de la inversión para el desarrollo económico a partir de la alta dependencia a las importaciones. El esfuerzo de ahorro supuso una limitación en el crecimiento y se convirtió en un obstáculo para superar la barrera de las importaciones en condiciones de una relativa igualdad en los ingresos para el conjunto de la población salario-dependiente en su totalidad. Esto último implicaba también una demanda relativamente baja, basada en ingresos que no diferenciaban entre los aportes de productividad y de innovación. En su conjunto, ello explica la limitación del crecimiento de los excedentes productivos, lo que hizo difícil el financiamiento endógeno (Tavares y Serra, 1971). 
Este complejo panorama pone sobre la mesa una discusión de vieja data en la región latinoamericana: ¿qué rol debe jugar el ahorro interno en el financiamiento del desarrollo? No obstante a ello, en el presente cubano ocurre un proceso de búsqueda de la inversión extranjera ${ }^{25}$ como un motor del desarrollo económico, en un contexto latinoamericano donde la IED está reforzando la especialización productiva y con ello, desajustes sociales y económicos (Cepal, 2015).

$\mathrm{Al}$ no existir un ahorro interno que permita desarrollar la capacidad de inversión en Cuba, se está acudiendo a acreedores internacionales cuya tendencia de inversión está relacionada con la re-primarización y la ampliación de las economías duales en toda la región (López y Belloni, 2014). La nueva Ley de IED de 2014 abre espacios de inversión que se corresponden con esa tendencia anteriormente descrita. Bajo la nueva política IED, existe un sobredimensionamiento en la inversión en turismo y en la minería. ${ }^{26}$ Un factor importante aquí es que en la nueva Ley parece estar orientada principalmente al mercado externo, utilizando una fuerza de trabajo cuyos ingresos estarán protegidos por la acción estatal. En la misma Ley se determina que "no habrá libre contratación de la fuerza de trabajo". Además, que el salario se condicionará a la

La Ley de Inversión Extranjera (Ley número 118 del 16 de abril de 2014), tiene como objeto: "la ampliación de los mercados de exportación, el acceso a tecnologías de avanzada, la sustitución de importaciones, priorizando la de alimentos. Del mismo modo a la obtención de financiamiento externo, la creación de nuevas fuentes de empleo, la captación de métodos gerenciales y la vinculación de la misma con el desarrollo de encadenamientos productivos, así como al cambio de la matriz energética del país mediante el aprovechamiento de fuentes renovables de energía" (Gaceta Oficial de la República de Cuba, 2014).

Entre los 246 proyectos que se proponen en la nueva ley de IED cubana, con un monto de inversión de 8700 millones de dólares (Sánchez y Castro, 2014) existen demandas dirigidas tanto al sector primario de la economía, como al desarrollo de la industria y los servicios. Sin embargo, las propuestas que están vigentes no están equilibrando los necesarios encadenamientos entre sectores; sino más bien, reflejan la tendencia a rehabilitar la producción primaria en áreas como: a) agricultura -el azúcar y la producción de carnes y alimentos-; b) la exploración y extracción petrolera, y c) la minería -extendiendo ésta a zonas centrales y orientales del país y abarcando minerales como cobre, níquel, sulfuros masivos hospedados en sedimentos básicamente carbonatados (tipo Irish), orogénicos y metales preciosos, metales base (cobre, plomo, zinc). En el sector terciario resaltan las demandas de tecnología, ingenierías, producción de biofármacos, proyectos tecnológicos y del sector turístico -este último con propuestas como el desarrollo inmobiliario para campos de golf y de infraestructura hotelera, los cuales visiblemente le apuestan al mercado de Estados Unidos-. Entre los proyectos se buscan financiamientos externos y que soslayen el emprendimiento interno, están los casos de: transporte, construcción, industria -producción de neumáticos, envases de aluminio, vasijas de vidrio y un sistema integrado de procesamiento de residuos sólidos- (véase Granma, 2015). 
eficiencia y el valor agregado que las empresas generen; quedando el pago del servicio de fuerza de trabajo a una negociación entre la entidad empleadora y la empresa de capital extranjero a partir de lo establecido por el Ministerio de Trabajo y Seguridad Social.

El hecho de que las inversiones están relacionadas principalmente con sectores primarios sin valor agregado, y que se delimite la incorporación de la fuerza de trabajo de una manera competitiva a este proceso, influye en la innovación y la productividad. En tanto ha sido ineficaz para crear estímulos para la innovación y la productividad, es precisamente el factor salario el que ha determinado históricamente los bajos rendimientos para crear excedentes y ahorro para la inversión. Por todo ello, es un asunto relevante cómo las inversiones de capital externo potenciarán la acumulación o ahorro interno y en qué sentido ampliarán o no el peso de la deuda externa en el desarrollo.

\section{EL CONFLICTO DE LOS ACTORES EN EL DESARROLLO}

Ante la lasitud en la integración de actores en disputa ${ }^{27}$ en el desarrollo cubano, por los propios conflictos que experimentan países como Venezuela, Bolivia, Ecuador y Brasil; y no obstante a los acuerdos de cooperación determinados por nuevos contextos de colaboración como lo son la Alianza Bolivariana para América (ALBA) y la Caribbean Community (CARICOM), en Cuba parece pervivir la cuestión de cómo potenciar el ahorro interno y el desarrollo endógeno con base al intercambio internacional, tendiendo un rol protagónico la perspectiva de incorporar actores externos en detrimento de los internos. No parece solucionada aún en un nivel político qué actores son los esenciales para superar la heterogeneidad o cómo desarrollar la innovación y la productividad sobre la base de las capacidades y habilidades internas. ${ }^{28}$

López y Belloni (2014) definen los proyectos de desarrollo de los años recientes en la región, de acuerdo a su compatibilidad con las estrategias neoliberales. Así, definen las naciones como: a) países neoliberales a aquellos que reproducen fórmulas de acoplamiento con las políticas comerciales, económicas y financieras provenientes de Estados Unidos, fundamentalmente, entre ellos: Chile, Perú, Colombia y Paraguay; como b) neodesarrollistas, a aquellos países que formulan estrategias de desarrollo contrarias en cierto grado al capital financiero internacional, entre ellos: Argentina, Brasil y Uruguay, y c) a países con proyectos de desarrollo en disputa, que mantienen estrategias de desarrollo antimperialistas y antisistémicas, entre ellos: Bolivia, Ecuador y Venezuela.

Para explicar las afirmaciones anteriores, abrimos un breve paréntesis que hace referencia a datos estadísticos sobre DH, que corroboran las aseveraciones previas. En 2014 -año en que se promulga una Ley de Inversión Extranjera en la isla-, Cuba está ubicada entre los países que 
La incertidumbre que plantea la extensibilidad a corto plazo de un equilibrio macroeconómico, conduce a una coyuntura en la que se contempla una reconfiguración de las relaciones internacionales. Así, cobra importancia la inclusión de un actor que históricamente ha condicionado la perpetuación de la heterogeneidad en toda la región y que en el caso de Cuba, conlleva a la reproducción de relaciones políticas ya contenidas en el pasado de la isla. Léase lo que sucedió en 1898, o posteriormente, con la política del Buen Vecino en 1930, o después de 1959. Ello, ante un Estado que confronta la cuestión de su continuación histórica, también por causas particulares.

La inclusión del nuevo -antiguo enemigo- actor en los esquemas de desarrollo del país periférico - un Estados Unidos con una nueva proyección política hacia Latinoamérica que bien se explica por la aquiescencia lograda en los últimos años por gobiernos anti-sistémicos y neo-desarrollistas en la región (López y Belloni, 2014)-, encierra una suerte de tácita transición "comprensiva" desde la concepción leninista de imperialismo (conflictos de clases y expansión de la acumulación, otrora excluyente en un sentido endógeno) a una -si el lector es tolerante- shumpeteriana; ${ }^{29}$ en la cual, se han digerido las relaciones internacionales predominantes como resultado de una coyuntura donde la disminución de fuerzas arbitrarias, ha orientado el conflicto hacia posiciones de diálogo. Desde un punto de vista teórico, esto último puede ser una explicación de la distención del histórico conflicto político en un país cuyas estructuras dependientes y heterogéneas son también el resultado de la acción geopolítica del mismo "nuevo" actor -que no es Noruega y que ahora, vuelve sobre el disimulo de la buena vecindad-.

Ante esa suerte de eco histórico, restaría conocer cuáles son las "nuevas" estrategias que el país periférico pretende establecer para contrarrestar la de-

internacionalmente mantienen un estándar de DH alto (lugar 67 en el Índice de Desarrollo Humano, véase UNDP, 2015). Ello, en sí determina la existencia de una fuerza de trabajo educada y saludable, con capacidades. A modo de ejemplo, en términos de educación y formación en las ramas que propone la Ley de Inversión Extranjera, existe fuerza de trabajo con calificación y capacidades de innovación. En 2014 se graduaron como técnicos medios: 474 en geología, minería y metalurgia; 1301 en energía; 2010 en construcción de maquinarias; 1015 en electrónica, automatización y comunicaciones; 1497 en transporte; 3279 en construcción; 8987 producción agropecuaria, entre otras especialidades. Se graduaron en el mismo año como universitarios: 5401 ciencias técnicas; 1624 en ciencias agropecuarias; 5285 en ciencias económicas; 22670 en ciencias médicas (ONEI, 2015b). El salario medio mensual a nivel nacional fue de 584 pesos cubanos, está de más decir que son insuficientes para cubrir las necesidades relacionadas con la existencia de los individuos en sociedad (ONEI, 2015a). 
pendencia y la heterogeneidad que éste manifiesta y que dan pie a la crisis sistémica que también contiene, de manera que no se repitan las experiencias de las primeras cinco décadas del siglo xx con el mismo "nuevo" actor. $\mathrm{O}$ aquéllas relacionadas con la experiencia con el socialismo real. Esta es una suerte de correlación evidente entre un pasado reciente y un presente contradictorio. La imaginación popular cubana, aún con la alerta martiana, admite al nuevo actor como una solución a problemas cotidianos. Lo cual, podría también verse como un fracaso en términos de desarrollo al no interrelacionar las experiencias pasadas con un futuro previsible.

\section{CONCLUSIONES}

Los actuales conflictos que enfrenta la reinserción de la estrategia de desarrollo cubana al sistema capitalista internacional, son el resultado del tácito soslayo a los factores que reproducen la HE y la dependencia. La continuidad de esa condición, supone en el futuro una relativa incapacidad institucional para resolver conflictos referidos al bienestar, a partir de que la desarticulación de los sectores de la economía, mantendrá las brechas entre las expectativas de movilidad social y las fuerzas heterónomas que las condicionan.

En un sentido histórico, el mantenimiento de ese carácter dependiente y heterogéneo, se corresponde con la subestimación del rol del Estado y con el sobredimensionamiento del papel de actores supranacionales en el desarrollo económico. Ello, en detrimento de actores endógenos que en la actualidad contienen capacidades sociales como un recurso de la economía y sociedad cubanas.

Con la concepción de inclusión de actores externos, la isla enfrenta la disyuntiva de cómo restringir la geopolítica de la apropiación diferencial de la riqueza, y con ello, de limitar la influencia del centro en la condición periférica. El socialismo, también enfrenta el reto de mitigar la exacerbación de las contradicciones y desintegración sociales y los conflictos humanos relativos al crecimiento de la pobreza y disminución del bienestar ante la limitación de la productividad y la innovación, aun teniendo una fuerza de trabajo capaz de lograr metas en ambas dimensiones. Una cuestión relevante en este sentido, es cómo lograr producciones con valor agregado que gradualmente disminuyan la necesidad de importación, para así competir de una manera ventajosa frente al deterioro de los precios de intercambio internacional, potenciando el ahorro y restringiendo la tendencia a la especialización productiva. 
El Estado, en tanto agencia del desarrollo, necesita consolidar un cambio estructural que subvierta los déficits en el financiamiento, en el ahorro interno y en el uso eficiente de los recursos. El desarrollo económico en este caso ha de procurar una integración del sistema productivo, a partir del cual se deben sostener cambios sociales anteriores, por medio de los cuales se han satisfecho necesidades humanas.

No obstante, ante la necesidad de importación, acumulación y financiamiento y ante el crecimiento potencial de la deuda externa que genera estas limitantes, se origina una circunstancia en la que se debaten procesos históricos que ya tienen antecedentes en la isla. Esto es, la incorporación de agentes externos, como es el caso de Estados Unidos -nación que ha condicionado la expansión de la política neoliberal en la región. Todo lo cual conlleva a un examen de cuáles podrían ser las consecuencias históricas de ese proceso para el mantenimiento de los logros sociales de desarrollo humano y equidad en la isla a partir del proceso de transición económica.

La desconexión política del socialismo al sistema mundial por más de medio siglo, aun cuando llegó a convertirse en un paradigma para fuerzas de izquierda en la región latinoamericana, no implicó per se una superación de la HE y la condición periférica. Este hecho en sí, cuestiona los referentes teóricos de la concepción de desarrollo cubana, y refuerza algunas de las nociones teóricas elaboradas en el ámbito latinoamericano para explicar las características de desarrollo. Entre ellas, las nociones de centro-periferia y de HE provenientes del estructuralismo y la teoría de la dependencia.

La profundidad de la dependencia cubana al sistema de intercambio global en el presente, supone el reto de elaborar una estrategia plausible, que limite los intereses de rentabilidad del capital internacional y proteja a su fuerza de trabajo de las dinámicas más recurrentes que hoy se pueden verificar en el ámbito de la globalización. Una de las formas de protección de la fuerza de trabajo es la incorporación de agencias y emprendimientos que, dentro de un marco de gobernanza, incluyan a sectores y actores cubanos dentro y fuera de la isla para generar nuevas oportunidades para el desarrollo, pero sobre todo en lo relativo a alianzas internas o endógenas basadas en la innovación y la productividad.

Para las distintas generaciones de cubanos la coyuntura actual, supone un proceso de reconfiguración de las normas sociales hasta ahora asimiladas. Con ello, se entrevera un cambio en el sentido común, que implica una mutación de las normas que condicionan los procesos de interacción y la solidaridad, ante fenómenos crecientes como la desigualdad, la pobreza y la inversión extranjera. Proceso que también necesita de referentes históricos, en tanto la 
explicación del presente no debería cimentarse en la destrucción del pasado, ni de los mecanismos sociales que vinculan las experiencias contemporáneas de los individuos con las de generaciones anteriores.

El crecimiento de estigmas y simbologías sobre bienestar y movilidad social asociadas al consumo, supone un crecimiento de metas asociadas a lo individual que, de no cambiar su trayectoria, harán prevalecer una preocupación por satisfacer necesidades inmediatas, sin examinar las consecuencias de ello para las generaciones futuras. Sea en una suerte de socialismo reconfigurado o, dentro de esquemas de desarrollo capitalista, la potencial ruptura del presente con el pasado de la isla, trascenderá como un retroceso aleatorio en cuanto al desarrollo. Reflujo que articulará niveles diferenciados de fracaso.

\section{BIBLIOGRAFÍA}

Cepal (2013), La inversión extranjera directa en América Latina y el Caribe, Unidad de Inversiones y Estrategias Empresariales, División de Desarrollo Productivo y Empresarial, Cepal, Santiago de Chile [LC/G.2613-P].

(2015), Inversión Extranjera Directa en América Latina y el Caribe, Cepal, Santiago de Chile [LC/G. 2641-P]

Furtado, Celso (1964), Dialéctica del subdesarrollo, México, Fondo de Cultura Económica.

(1966), Subdesarrollo y estancamiento en América Latina, Buenos Aires, EUDEBA.

(1967), Teoría y política del desarrollo económico, México, Fondo de Cultura Económica.

(1984), Desarrollo y Subdesarrollo, Buenos Aires, EUDEBA.

(1993), Los vientos del cambio, México, Fondo de Cultura Económica.

Gaceta Oficial de la República de Cuba (2014), Ley de Inversión Extranjera, No. 20, 16 de abril [Ministerio de Justicia, La Habana].

Galeano, Eduardo (1971), Las venas abiertas de América Latina, México, Siglo XXI Editores.

Granma (2015), Cartera de oportunidades para la inversión extranjera, 2015, disponible en <http://www.granma.cu/file/sp/cartera-de-oportunidadesde-inversion-extranjera-23/datos/documentos/Cartera\%20de\%20Oportunidades\%20de\%20Inversi\%C3\%B3n\%20Extranjera\%202015.pdf>, [recuperado el 10 de mayo de 2015].

Hobsbawm, Eric (1994), Historia del siglo XX, Buenos Aires, Grijalbo. 
Kay, Cristobal (1989), Latin American Theories of Development and Underdevelopment, New York, Routledge.

(1991), "Teorías latinoamericanas del desarrollo", Nueva Sociedad, núm. 113, mayo-junio.

Lenin, Vladimir. I. (1902), Imperialism: The Highest Stage of Capitalism, New York, International Publishers.

López, Emiliano y Paula Belloni (2014), "Las dinámicas del capital transnacional en América del Sur y los 'nuevos' patrones de dependencia: tendencia de re-primarización exportadora en el siglo xxI”, Mundo Siglo XXI, núm. 34, vol. X.

Lowenthal, Abraham F. (ed.) (1991), Exporting Democracy: The United States and Latin America, Case Studies, Baltimore, The John Hopkins University Press.

Marini, Rui Mauro (1977), Dialéctica de la dependencia, México, Ediciones Era.

Martínez Heredia, Fernando (2005), En el horno de los noventas, La Habana, Ciencias Sociales.

(2008), El ejercicio de pensar, La Habana, Ruth Casa Editorial.

Oficina Nacional de Estadísticas e Información (2015a), Anuario Estadístico de Cuba 2014. Empleo y salarios. Disponible en http://www.one.cu/ aec2014/18\%20Educacion.pdf [recuperado el 10 de octubre de 2015].

Oficina Nacional de Estadísticas e Información (2015b), Anuario Estadístico de Cuba 2014. Educación. Disponible en http://www.one.cu/ aec2014/07\%20Empleo\%20y\%20Salarios.pdf [Recuperado el 10 de octubre de 2015].

Portell Vilá, Herminio (1943), "Deuda flotante”, Bohemia, año 35, núm. 36, La Habana, septiembre 5.

(1943a), "Diversificación agrícola", Bohemia, año 35, núm. 41, La Habana, octubre 10.

Prebisch, Raúl (1949), El desarrollo económico de América Latina y algunos de sus principales problemas, Cepal, Santiago de Chile.

(1963), Hacia una dinámica del desarrollo latinoamericano, México, Fondo de Cultura Económica.

Quijano, Aníbal (2000), "Colonialidad del poder, eurocentrismo y América Latina”, en Edgardo Lander (comp.), La colonialidad del saber: eurocentrismo y ciencias sociales. Perspectivas latinoamericanas, Buenos Aires, ClAcso.

Rostow, Walt Whitman (1960), The Stages of Economic Growth: a Non Communist Manifesto, Cambridge, Inglaterra, Cambridge University Press ( $3^{a}$ edición /1990). 
Sánchez Arango, Aureliano (1960), Reforma Agraria, La Habana, Frente Nacional Democrático Triple A.

Sánchez, Lorena y Yudy Castro (2014), "Presentará Cuba cartera de oportunidades para la inversión extranjera", Granma, 3 de noviembre.

Schumpeter, J. (1965), Imperialismo. Clases Sociales, Madrid, Tecnos.

Scribano, Adrián (2008), "Hacia unas ciencias sociales del sur. Pensar las prácticas autonómicas entre el imperialismo, la dependencia y el neo-colonialismo", Pensamento Plural, UFPel Pelotas, Brasil [08]: 11-36 janeiro/junho 2011.

Sen, Amartya (1998), Bienestar, justicia y mercado, Barcelona, Paidós. (1999), Development as Freedom, New York, Random House.

Stiglitz, Joseph E. (1998), Towards a New Paradigm for Development, 9th United Nations Conference on Trade and Development, Raúl Prebisch lecture, Delivered at the Palais des Nations Geneva, 19 October 1998, http:// unctad,org/en/Docs/prebisch9th,en,pdf [Recuperado el 14 de julio de 2012].

Svampa, Maristella (2013), "Consenso de los Commodities y lenguajes de valoración en América Latina”, Nueva Sociedad (244), marzo-abril.

Tavares, María da Conceição y José Serra (1971), "Más allá del estancamiento. Una discusión sobre el estilo de desarrollo reciente del Brasil”, El Trimestre Económico, vol. xxxvıII (152), México, octubre-diciembre.

undp (2015), Human Development Index and its Components. Disponible en http://hdr.undp.org/es/composite/HDI\#s [Recuperado el 10 de octubre de 2015].

Vidal Alejandro, Pavel (2008), La disyuntiva actual de la política económica cubana, La Habana, Centro de Estudios de la Economía Cubana. (2009), El salario real y la productividad en Cuba: actualización, La Habana, Centro de Estudios de la Economía Cubana. 